\title{
Cultura de história, história pública e ensino de história: investigação e formação de professores de história
} Culture of History, Public History, and History Teaching: The Investigation and the Training of History Teachers

\author{
Marcelo Santos de Abreu *, \\ Nara Rúbia de C. Cunha ${ }^{* *, 2}$
}

\section{RESUMo}

$\mathrm{O}$ artigo avalia a maneira como estudantes de história se relacionam com a cultura de história. Primeiro, discutimos as relações entre cultura de história, história pública e ensino de história. Na segunda parte, avaliamos as políticas de formação e defendemos a investigação como princípio educativo para a formação. Na última, apresentamos a experiência de produção de narrativas curtas produzidas pelos estudantes sobre a cultura de história. Nas três partes, trazemos as vozes dos estudantes e sua reflexão sobre a cultura de história. Defendemos que esse método pode ser útil no questionamento das relações sensíveis e racionais que mantemos com a história.

Palavras-chave: cultura de história/história pública; ensino de história; formação de professores de história.

\section{Abstract}

The article assesses how students of History relate to the culture of History. First, we discuss the relationships between the culture of History, public History, and the teaching of History. The second part evaluates the policies for the formation of History teachers and defends research as an educational principle for their training. In the latter, we present the experience of producing short narratives produced by students about the culture of History. In the three parts, we bring the students' voices and their reflection on the culture of History. We argue that this method can be useful in questioning the sensible and rational relations that we maintain with History.

Keywords: culture of History/Public History; teaching of History; training of History teachers.

\footnotetext{
* Universidade Federal de Ouro Preto (Ufop), Departamento de História, Ouro Preto, MG, Brasil.marcelo.abreu@ufop.edu.br

** Escola Estadual D. Pedro II (rede estadual de ensino de Minas Gerais), Professora de História, Belo Horizonte, MG, Brasil.nrcdois@yahoo.com.br
} 
“Eu queria ser egiptóloga” é o título de uma memória ${ }^{3}$ escrita por uma estudante acerca de seu interesse pela história. Segundo a autora, sua inclinação teria começado

com uma história em quadrinhos distribuída dentro das páginas das revistas Recreio; talvez tenha sido o teor aventuresco da história ou o fato de uma das personagens principais compartilhar do meu nome, mas a partir daquela leitura teve início a minha fase de obsessão pelo Egito antigo. HQs, documentários do Discovery Channel, publicações com títulos duvidosos como "Tudo que você precisa saber sobre o Egito Antigo", filmes de ficção, tudo que eu pudesse achar sobre o tema aumentava ainda mais minha curiosidade. Obviamente, metade das coisas com as quais tive contato naquela época eram sem embasamento científico algum, mas sem dúvida criaram dentro de mim um desejo pela exploração dos tempos e dos espaços. Depois do Egito antigo veio a fase medieval, a fase Inglaterra vitoriana, a fase exploração espacial... (Discente do curso de Licenciatura em História, 21 anos, 2017)

Notem que o texto destaca a diversidade de materiais que compuseram seu interesse: revistas dedicadas ao público infanto-juvenil, como as histórias em quadrinhos, documentários televisivos, filmes de época. E que os interesses se sucediam ou acumulavam do Egito antigo à Inglaterra vitoriana, do mundo medieval às viagens espaciais. Por um lado, portanto, a memória nos fala de uma curiosidade que se move entre temas e produtos diversificados. Por outro, o próprio movimento da lembrança já implica uma postura reflexiva enunciada desde o presente: acusa a carência de cientificidade do que apreciava, aponta razões estéticas para seu gosto - "talvez tenha sido o caráter aventuresco da história" -, revela a intensidade da relação com o passado - "minha obsessão pelo Egito" - que esses objetos potencialmente despertavam e despertam. Por que que essa breve passagem nos inspira a pensar o ensino e a formação de professores de história?

O ensino de história há muito se entende como uma das formas de compreensão e fruição da relação entre passado, presente e futuro. Isto é, a área se reconhece como parte do movimento de compreensão dos tempos que nos constituem e, ao fazê-lo, cremos que matiza o viés normativo que acompanha a constituição das disciplinas escolares (Abud, 2011; Bittencourt, 2001; Monteiro, 2003; Gabriel, 2000). No entanto, nas definições do que seja o ensino 
de história e qual sua tarefa reforça-se sempre o aspecto do entendimento racionalmente controlado da experiência histórica, enfatizando-se a necessidade de que ensinemos e aprendamos a progressivamente utilizar as categorias e formas próprias de uma disciplina (Abreu; Rangel, 2015). Porém, ao definir-se como saber escolar, admite-se com sabedoria que os sujeitos da aprendizagem carregam e elaboram compreensões e apreensões da história que antecedem seu ensino sistemático. Não só antecedem, como continuam ao longo do processo. Assim, a atenção que vem sendo direcionada às representações sociais no ensino da história nos leva a pensar como a memória social é uma determinação anterior, bem como a considerar devidamente as representações e apresentações da história pela indústria cultural, que buscam moldar a percepção dos estudantes assim como as nossas. Daí a necessidade de pensarmos como as formas públicas da história ou as maneiras variadas de popularização do passado configuram a curiosidade histórica. Muitos trabalhos apontaram essas relações e como o fenômeno acontece na escola, mas parece que damos pouca atenção a isso quando nos envolvemos na formação de professores de história. A atenção que os futuros professores e formadores devem ter sobre esse fenômeno poderia começar com uma anamnese do papel desempenhado por aquelas formas na constituição de seu interesse e curiosidade.

Assim, procuramos pensar, neste artigo, dois movimentos: primeiro, consideramos a relação entre cultura de história, história pública e ensino de história; depois, apresentamos uma atividade de formação de licenciandos, que se concentra na apresentação de memórias dos estudantes acerca da cultura de história. Na primeira parte, desenvolvemos, também recobrando as narrativas elaboradas como a que citamos acima, as distinções entre cultura de história e história pública, evidenciando que esta, como também o ensino escolar da história, se integram ao universo mais amplo da primeira. Na seção seguinte, inicialmente avaliamos as propostas de formação de professores de história. Em seguida, apresentamos o trabalho realizado, que propõe a escrita de pequenas narrativas sobre as memórias da escola ou da cultura de história como ponto de partida para a reflexão sobre o ensino de história e seus desafios em um mundo carregado de passados e, para alguns, esquecido do futuro (Huyssen, 2007). 
CUlTuRA DE HistóRIA, HISTÓRIA PÚBLICA E ENSINO DE HISTÓRIA

Uma/um estudante foi convidada/o a refletir sobre sua relação com a história, particularmente com as maneiras de representar o passado que circulam além da escola:

Das coisas que me sobem a consciência, recordo bastante da relação dos meus pais com a cidade onde nasci e cresci até o dia que me mudei para Mariana. Durante toda minha vida, meus pais sempre tiveram esse hábito de recordar suas memórias do passado naquela região da zona da mata. Através das experiências e relatos dos meus pais fui acessando camadas de passados, passados que para mim eram difíceis de inserir em qualquer narrativa num primeiro momento da minha vida, mas com o tempo e com os conteúdos absorvidos em leituras e aulas de história fui percebendo a historicidade da minha própria cidade e de suas mudanças numa linha temporal mais geral. Algumas experiências de passado se apresentavam para mim através de relatos ou através de estátuas pela cidade como a de um certo coronel Serafim Tibúrcio da Costa que mudou-se para aquela localidade por volta de 1880 e que acabou sendo personagem de um acontecimento que nos diz muito da história do Brasil naquele momento, tanto quanto conta a história dessa região e de indivíduos comuns. O tal coronel Tibúrcio ao perder uma reeleição em 1894 e por volta de 15 de maio de 1896, reuniu cerca de 800 de homens e tomou o poder a força, declarando São Lourenço do Manhuaçu uma REPÚBLICA! Não tardou que forças estaduais viessem e reprimissem os sediciosos que fugiram em direção ao Espírito Santo. [Discente do curso de licenciatura em história, 26 anos, 2017]

Essa breve narrativa, provocada por um exercício nas aulas de estágio supervisionado, revela a complexidade da formação de professores de história. Como já notamos anteriormente, os estudantes são sujeitos de conhecimento imersos num mundo no qual modalidades de apresentação da história se sobrepõem. Percebemos aqui a sofisticação do pensamento que o ato de recordação provoca. Por curta que seja, a narrativa recobra um tempo passado marcado pela presença da história na memória familiar. Também imerso em um processo formativo definido pelo pensamento conceitual, o/a estudante mobiliza ideias e categorias que lhe são próprias: "consciência", "camadas de passados", "historicidade" etc. O relato comunica dois momentos de seu 
engajamento com a história. Ao trazer o seu passado ao presente reflexivo, o/a estudante reelabora seu percurso e opera as relações entre as formas da história disponíveis no passado e no seu momento formativo. O movimento do/da estudante e de outros/outras nos inspira a interrogar as categorias que usamos para pensar essas relações.

Cultura histórica se tornou a categoria mais comum nos trabalhos dedicados a pensar as relações da historiografia e do ensino de história com outras maneiras de relacionamento e formas de representação do devir humano com ênfase sobre as relações variadas com o passado. Pensar a relação entre ensino de história e o universo da história pública nos leva a questionar o uso daquela categoria, muitas vezes utilizada sem precisar sua conceituação. Mas também propor uma alternativa que abarca as experiências diversas que se realizam sob a hegemonia do conceito moderno de história. Trata-se de pensar como a noção de cultura de história é adequada à situação presente, sem almejar à normatividade que determinadas definições de cultura histórica carregam.

É possível identificar, ao menos no universo da produção brasileira, duas referências essenciais para definir cultura histórica. Uma primeira se populariza através de História e memória (2003), livro de Le Goff que se tornou canônico. Na verdade, Le Goff se inspirava no livro de Bernard Guenée sobre a cultura histórica no Ocidente medieval, um estudo de história da historiografia que analisou a relação subalterna da história com a teologia e o direito, o corpo de autores que escrevia história, as condições de recepção e seus usos políticos. O que escreveram, como o fizeram e as condições da interpretação das narrativas indicavam, para Guenée, uma cultura histórica que ultrapassava os textos e amparava a legitimação da sociedade e suas instituições num passado imaginado (Guenée, 1980, p. 16). Le Goff derivou daí a ideia de que a cultura histórica é "a relação que uma sociedade, na sua psicologia coletiva, mantém com o passado", acrescentando que sua concepção não estava "muito afastada daquilo a que os anglo-saxônicos chamam 'historical mindness"' (Le Goff, 2003, p. 47-48). A relação com o campo da história das mentalidades é mais do que evidente, mas também se surpreende a conexão com a ideia de consciência histórica enquanto racionalização de um passado articulado ao presente e ao futuro. 
A segunda definição se liga à teoria da história de Jörn Rüsen e é a mais difundida contemporaneamente (Lucini; Oliveira; Miranda, 2007; Schmidt, 2017; Schmidt; Garcia, 2006). Na teoria da história de Rüsen, a cultura histórica é o campo de interação da razão histórica na articulação do passado para a orientação do agir no presente (Rüsen, 2010, p.121). Nesse sentido, qualquer objeto ou procedimento configurando as relações temporais integra a cultura histórica, porque seria a expressão dessa forma particular e universal do entendimento, a razão histórica. Mas Rüsen também admite que essa razão não se manifesta desencarnada de determinações sensíveis ou emocionais que escapariam, em princípio, ao esforço racionalizador propriamente humano note-se que a teoria de Rüsen pressupõe a existência desse humano universal e suas constantes antropológicas. Portanto, além da historiografia e da didática da história, haveria uma variedade de formas da cultura histórica. Essa oscila entre dois aspectos do entendimento - razão política e razão estética. Tais aspectos seriam mediados pela formação histórica, e a história escolar seria uma das maneiras de organização desta. A mediação se daria, por um lado, porque a formação histórica poderia flexibilizar argumentos legitimadores da razão política e evitar a instrumentalização mútua entre ciência e poder. E, por outro, porque essa instância crítica refrearia os efeitos negativos da "aparência sedutora" dos aspectos estéticos sobre a "visão da realidade" (Rüsen, 2010, p. 127-131; Abreu; Rangel, 2015, p. 18-19). Ora, a formação histórica, nesse sentido, está comprometida com uma dimensão de orientação do presente que, se não afasta completamente a apreciação estética inerente à apresentação/ representação do passado ou à fruição direta dos objetos e artefatos que o presentificam, almeja a racionalidade integral (poderíamos dizer também ideal) das projeções de futuro que orientam a ação, isto é, a antecipação desse movimento na consciência.

Assim, cremos que, para Rüsen, cultura histórica e consciência histórica se confundem e, na medida em que a formação histórica se intensifica, a consciência histórica se aperfeiçoa. Por isso, ao contrário do que o próprio autor e seus comentadores defendem, há na verdade uma hierarquia e uma progressão necessárias entre os tipos-ideais da cultura histórica/consciência histórica. As formas tradicional, exemplar, crítica e genética podem ser, e são, segundo o autor, simultâneas - em nosso tempo, pelo menos. Mas Rüsen de fato preconiza, e talvez tenha razão, que a forma genética, que se caracteriza pelo 
relativismo e controle racional dos argumentos que fazem uso do passado face ao presente, seja superior na razão quando comparada às demais. Em poucas palavras, embora o autor recuse ou não se comprometa a discutir isso, há sim um telos e, por que não dizer, um progressivismo inerente à classificação das diferentes formas da consciência histórica. Sim, é evidente, de nosso ponto de vista, que tal maneira de compreender a cultura histórica/consciência histórica permite programar a formação histórica. Daí também o sucesso dessa teoria na área de ensino de história, seja na análise ou na organização prática do trabalho escolar.

Uma observação, contudo, é necessária: o modo como se conceitua a cultura histórica/consciência histórica e se apresentam suas modalidades ao longo do tempo é uma teoria ancorada no conceito moderno de história que, todos sabemos, tem sua historicidade. Reconhecer isso implica considerar que, por um lado, sempre houve e haverá formas alternativas de relacionamento com o passado e de imaginação da ação histórica (Seth, 2013). Por outro, tais formas não são completamente redutíveis ou integradas a um modelo de consciência histórica, notadamente o genético, e por isso mesmo não são domesticadas pelo modelo disciplinar que constituiu a pesquisa histórica e seu ensino. Por isso, parece-nos mais adequado pensar em termos de uma cultura de história e, a partir disso, compreender o ensino escolar da história e a história pública como parte dela.

Uma cultura de história se constituiu a partir do momento em que, desde os finais do século XVIII, o passado se popularizou em formas as mais variadas (Berger; Lorenz; Melman, 2011; Paletschek; Korte, 2012; Araújo; Ramos, 2015). Os diferentes casos nacionais estudados por esses autores identificam a popularização e a presentificação do passado em teatro, museus, monumentos, diferentes gêneros literários, práticas populares de colecionismo e outros meios, que estabeleceram um gosto pela história, necessário ao surgimento de uma história científica (Abreu; Bianchi; Pereira, 2018, p. 282-283). Num ambiente de mudanças aceleradas, a cultura de história englobaria o desenvolvimento da ciência da história, seu ensino e formas menos sistemáticas de apreensão e apresentação do passado-presente, e se caracterizaria pela circularidade. Segundo Billie Melman (2006), numa cultura de história as imagens populares e aquelas produzidas por uma elite ou segundo preceitos disciplinares compõem um circuito de produção da história no qual os consumidores não 
recebem essas imagens passivamente. Ao contrário, eles colaboram ativamente na sua significação e ressignificação no curso de usos bastante variados - do lazer à identificação política, do aprendizado aberto pela proliferação das instituições de memória ao ensino organizado etc. O que Melman descreve se assemelha à noção de consumo como bricolagem defendida por Certeau em A invenção do cotidiano (2008). Para a autora, a atividade dos consumidores atingiria uma "produção secundária ou até mesmo uma coprodução da cultura" (Melman, 2006, p. 18). Podemos dizer que, ao contrário da noção de cultura histórica em cujo cerne percebemos uma hierarquia entre formas de consciência, a cultura de história se produz na circularidade entre materiais e procedimentos distintos circunstancial e assimetricamente posicionados no mundo da cultura.

Foi a intensificação dessa circularidade que produziu as condições de emergência da história pública. Esta surge nos anos 1970, como uma modalidade de engajamento dos historiadores de ofício com a produção do passado-presente para públicos que ultrapassavam os domínios disciplinares, como a escola e a academia (Almeida; Rovai, 2011). Desde seus começos, a história pública significava mais do que um campo profissional, e sim uma forma de atuação profissional engajada com o público, o que supunha reconhecer a legitimidade dos lugares e compreender as maneiras singulares através das quais o passado era/é reconstruído e utilizado popularmente (Grele, 1981). Ao longo desse engajamento e na medida em que a prática da história pública se desenvolvia, a reflexão sobre esse processo levaria a pensar a história pública e seus espaços como situações em que a autoridade sobre o passado-presente é partilhada e negociada (Frisch, 1990, p. xxi-xxii). Isto é, ao mesmo tempo que se reconhece a pertinência dos conhecimentos próprios à historiografia, a bagagem do público também precisa ser considerada, incluindo as tonalidades que a autoridade cultural expressa entre os grupos com os quais se trabalha. Aqui, então, podemos dizer que há certa coincidência com as preocupações do ensino de história se admitirmos também que a sala de aula é um lugar de produção de conhecimento e autoria partilhada centrada na aula.

A aula seria um momento caracterizado pela tradução, no qual o professor se vale do conhecimento historiográfico acumulado, mas também das formas da história que circulam mais amplamente. Nesse movimento, o que se produz seria um texto oferecido à leitura imediata dos estudantes. Nas leituras - a aula 
começaria verdadeiramente com as perguntas -, o texto se amplia, outras referências culturais são agregadas, novas possibilidades de autoria se configuram. Por isso, a aula é lugar de autoria partilhada mais (in)tenso do que a própria historiografia que lhe serviu de referência (Mattos, 2002).

A relação entre história pública e ensino de história sugere algumas perguntas. Como formar os futuros professores para atentar à complexidade de sua tarefa como mediadores da compreensão da história e do exercício de autoria? Como criar uma formação docente que de fato conjugue a história escolar e os espaços que podemos identificar como o terreno da história pública, tais como as revistas e outros meios de divulgação, o patrimônio e os museus, os documentários e outros meios audiovisuais contemporâneos? Finalmente, como formar para compreender a experiência histórica e exercitar sua reconstrução em meios variados, considerando suas dimensões racionais e sensíveis? Acreditamos que um projeto de formação de professores de história deveria proporcionar aos estudantes movimentos semelhantes àquele expresso na narrativa que abre esta seção: ouvir as vozes do passado, circular pela cidade interrogando seus monumentos, produzir o gesto reflexivo que elabora essas experiências. Em poucas palavras, a formação deveria se sustentar também na interrogação da cultura de história.

\section{FORMAÇÃO DE PROFESSORES E INVESTIGAÇÃO COMO POSTURA}

Oferecemos mais uma narrativa que materializa o que nós, formadores, percebemos cotidianamente. É uma das evidências recolhidas sobre a precedência das modalidades da cultura de história em relação ao processo de formação.

Meu interesse pelo estudo da História veio primeiro que o interesse pela docência. Em dois momentos: o primeiro contato e interesse se deu da forma mais esdrúxula possível através do canal History Channel. Apesar de hoje enxergar o quanto aqueles programas tinham algo de exagerado e até mentiroso em certo ponto, é inegável o poder de atração que ele exerce sobre as pessoas, sobretudo crianças; era impossível aliens, civilizações nativas da América e asiáticos viajantes não serem interessantes. $\mathrm{O}$ segundo e primordial interesse pela história se dá através de um jogo de computador, lançado no ano de 2005 pela Microsoft Games 
Studios, chamado Age of Empires III. O jogo tratava de guerras fictícias dos europeus em terras da América, existiam indígenas, mercenários e tudo mais. Fascinante na época em que comecei a jogá-lo e até hoje pareço uma criança no parque de diversões quando tenho tempo de jogar. Entretanto, hoje percebo que o game traz personagens históricos que não eram contemporâneos entre si, mas na época isso para mim pouco importava, o que valia era ver as tropas de Mauricio de Nassau contra as de Napoleão. [Discente do curso de licenciatura em história, 21 anos, 2017]

Essa recordação também foi produzida no curso de estágio supervisionado. O exercício que propusemos, e que será descrito em seguida, busca superar certas concepções limitadoras desse momento de formação, que vêm sendo questionadas há algum tempo, especialmente nos últimos 17 anos, quando houve mudanças significativas na organização das licenciaturas. As mudanças almejavam superar a dicotomia entre o aprendizado dos conteúdos, incluindo as habilidades de pesquisa, que constituem os objetos de ensino e os saberes pedagógicos sobre o objeto de ensino. Vale perguntar se tal divisão do processo de formação teria sido superada e como poderia ser. Para isso, vamos primeiro descrever a situação geral em que nos encontramos e que nos levou às práticas reflexivas desenvolvidas em nosso curso.

Os estágios tiveram sua carga horária quadruplicada e passaram a estar presentes desde a segunda metade do curso, não mais apenas no último ano de formação do licenciando. As mudanças foram definidas pelas resoluções do Conselho Nacional de Educação, ${ }^{4}$ que estão relacionadas à Lei de Diretrizes e Bases da Educação de 1996. Elas traduzem antigas lutas e demandas de especialistas do campo da formação docente para superar o modelo conhecido como " $3+1$ " e os problemas a ele ligados. Tal modelo se caracteriza por 3 anos de estudos na área disciplinar e um ano de formação pedagógica, promovendo o afastamento entre conhecimento específico e conhecimento pedagógico e acirrando a separação entre teoria e prática, ensino e pesquisa. Segundo Luís Fernando Cerri (2013), essas separações teriam antecedentes históricos mais antigos, mas se consolidaram após serem implantados os primeiros cursos de licenciatura no Brasil, na década de 1930. A divisão se acentuou a partir da reforma universitária de 1968, quando a formação foi dividida em espaços institucionais separados, sendo a formação pedagógica transferida para as faculdades de Educação, no caso das licenciaturas plenas, ou para cursos de 
complementação, no caso das licenciaturas curtas. Essa mudança fortaleceu ainda mais a separação entre os conhecimentos disciplinar e pedagógico e favoreceu a formação tecnicista ou instrumental, na qual o professor é visto como um organizador dos processos de ensino-aprendizagem, não como um intelectual crítico e pesquisador, capaz de refletir sobre o conhecimento disciplinar e seu próprio ofício para reelaborá-los em diferentes cenários e ambientes (Diniz-Pereira, 2013; Contreras, 2002). Tal concepção ainda é uma tendência, embora seja questionada e combatida por outras que despontam desde as décadas de 1980 e 1990, como a do professor como educador/agente de transformação e a do professor reflexivo (Diniz-Pereira, 2013; Zeichner, 2013).

Acreditamos que aquelas resoluções e as diretrizes de formação docente que lhes são correlatas expressam o conflito entre essas tendências. Embora o conceito de professor reflexivo perpasse todo o discurso apresentado pelas diretrizes, é necessário estar atento à perspectiva em que está sendo empregado, visto que, como apontam alguns especialistas, seus sentidos têm sido esvaziados em muitos casos. Há muito os críticos têm advertido quanto à necessidade de conceber a reflexão como ato crítico, coletivo e emancipador. Nesse sentido, faz-se necessária a compreensão do processo educativo numa esfera mais ampla, que envolve dimensões políticas, econômicas, culturais e socialmente circunstanciadas, na qual a docência se institui como ofício, como profissão que exige saberes próprios. Essa maneira de conceber a educação e a formação visa fortalecer a figura docente (Zeichner, 2008; Contreras, 2002). De acordo com ela, o professor é um profissional em formação constante e, como tal, sempre reflete sobre sua prática.

Contudo, Kenneth Zeichner (2008) adverte que, sob o slogan da reflexão, tem-se promovido um movimento de formação contrário à potencialidade dessa perspectiva de formação. Assim, ao invés de reagir à instrumentalização técnica, o conceito pode justificar e reforçar um esvaziamento da profissão. Se a reflexão se vincula primordialmente a um aprimoramento individual, a partir de condições e formações anteriores, ela pode ser usada para justificar modelos formativos em que o ato reflexivo se restringe às práticas e saberes da docência e não às matérias de ensino, aos objetos conceituais e disciplinares que têm sua autonomia. Nesse registro limitado, formar professores reflexivos torna-se um jargão. A tendência seria manter o docente como participante relativamente passivo no processo educativo, mero cumpridor de tarefas, transmissor de 
conteúdos e desenvolvedor de habilidades definidas prévia e externamente a cada circunstância. Essa é uma tendência possível, quando combinada à definição de modelos curriculares balizados por políticas de avaliação massiva alheias às especificidades das diferentes realidades escolares. Há, em nossa percepção, um problema iminente. Por um lado, a noção de professor reflexivo pode ser esvaziada quando o objeto da reflexão é limitado, como dissemos acima. Por outro, ela também se torna fraca quando a separação entre pensar os saberes pedagógicos e os disciplinares e acentua. Assim, as mudanças quantitativas promovidas nos estágios podem se tornar inócuas se a mentalidade $3+1$, enquanto baluarte das separações, não for superada nos cursos de formação docente (Cerri, 2013) e se não vierem acompanhadas de mudanças efetivas nas concepções de estágio e de formação (Pimenta; Lima, 2006).

Para as pesquisadoras Selma Garrido Pimenta e Maria do Socorro Lima (2006), romper com o modelo $3+1$ favorece a superação da visão de estágio como apêndice curricular, mas para ir além da instrumentalização técnica é essencial romper também com a concepção de estágio como imitação de modelos, na qual ele se confunde com o ato de observar o professor para copiar, refutar ou reelaborar sua prática, "sem proceder a uma análise crítica fundamentada teoricamente e legitimada na realidade social em que o ensino se processa" (Pimenta; Lima, 2006, p. 8). Na contramão dessa concepção, as autoras defendem que o estágio se constitua como atividade de pesquisa e que seja reconhecido como campo de conhecimento com estatuto epistemológico próprio, sendo produzido na interação do curso de formação com o campo social em que as práticas educativas são desenvolvidas - incluindo, no caso da formação de professores de história, o universo amplo da cultura de história e outras formas de atuação profissional como a história pública. Conceber o estágio como pesquisa pressupõe outra postura diante do conhecimento, tratando de "considerá-lo não mais como a verdade capaz de explicar toda e qualquer situação observada”, o que levaria os estagiários a assumir posturas normativas - vinculadas ao campo disciplinar ou aos saberes pedagógicos - em relação à atuação dos professores, isto é, levando a "dizer o que os professores devem fazer”. Ao contrário, o estágio deveria ser o momento em que se busca "novo conhecimento na relação entre as explicações existentes e os dados novos que a realidade impõe e que são percebidas na postura investigativa" (Pimenta; Lima, 2006, p. 14-15). 
Nesse modelo, o estagiário se identificaria com a figura de professor-pesquisador. É um desafio para os cursos de formação prepará-lo para assumir a investigação como postura, não como ação pontual. Nesse sentido, pode-se dizer, por exemplo, que trabalhos finais de licenciatura (TCC, monografias etc.) ou os relatórios de estágio não seriam suficientes, a não ser quando intencionalmente articulados aos demais momentos formativos. Superar as ações pontuais implica instituir a investigação como princípio estruturante da formação; e organizá-la segundo esse princípio requer o desenvolvimento da "investigação como postura", isto é, conceber o professor em formação "como protagonista no percurso de investigar, de tal forma que possa compreender o que está sendo construído dentro e fora da sala de aula, o que o leva a questionar seu papel social" (Pesce; Andre, 2012, p. 43). Nesse sentido, retomando a ideia de autoria e autoridade partilhada, trata-se de exercer a autoria em ambientes colaborativos desde os momentos iniciais do processo, mas especialmente ao longo dos estágios. Para Pesce e Andre (2012), as propostas curriculares de licenciatura que assumem a investigação como postura devem investir na criação do que chamam de ambiência de investigação, que não se limita apenas a uma atividade pontual de pesquisa, devendo haver uma mobilização de todo o curso para que isso se efetive. Logo, a organização do currículo deve convergir para esse fim, não apenas um componente curricular. De todo modo, os estágios supervisionados seriam momentos importantes para intensificar essa ambiência.

No modelo de estágio que praticamos, temos buscado articular as considerações anteriormente apresentadas às demandas próprias da formação específica em história, levando em consideração os principais problemas apontados por pesquisadores. Entre eles, destacamos: 1) um domínio fraco dos procedimentos da pesquisa histórica (Villalta, 1992-1993; Nadai, 1993) ou o descompasso entre a "mobilização de procedimentos teórico-metodológicos e a identificação destes como elementos ligados à pesquisa histórica" (Pereira; Hermeto, 2012, p. 34); 2) o desafio de atuar dentro e fora da escola como mediador das relações da sociedade com diferentes representações da história, isto é, "ser capaz de manejar a produção de saberes e a crítica dos saberes produzidos, com capacidades técnicas para desenvolver essa função intelectual na escola e em todas as demais instituições e espaços sociais" (Cerri, 2013, p. 179). Além disso, apontamos a dificuldade de relacionar as experiências 
singulares a uma experiência histórica mais ampla, dificuldade que acaba por reforçar desenraizamentos espaço-temporais e a fragmentação das relações sociais (Galzerani, 2008; Ciampi, 2015). Esclarecendo, esse último problema diz respeito à dificuldade de transformar as próprias memórias relativas à cultura de história, a observação das aulas nas escolas e as apresentações da história nos domínios da história pública em objeto de questionamentos que levem a relativizar o lugar da história acadêmica e a condição de professor em formação.

Assim, no currículo proposto, preconizamos momentos dedicados a intensificar a reflexão e a prática do ensino de história em sua relação com a cultura de história e a história pública. Em termos de estrutura e progressão, criamos dois momentos: nos estágios 1 e 2, o foco recai sobre a cultura escolar e o ensino escolar da história, já nos estágios 3 e 4 nos concentramos na relação entre a escola e espaços não escolares, com especial atenção para o patrimônio, a cidade e os museus como espaços de atuação dos historiadores e meios do ensino de história. No que se refere à prática de ensino e seu registro, desenvolvemos ao longo de cada estágio a crítica aos materiais didáticos e demais objetos da cultura de história que atravessam o ensino escolar, os estudantes planejam intervenções a partir da observação dos seus respectivos campos e registram as observações e resultados das ações nos relatórios. Nada muito diferente das práticas já consolidadas para esse momento formativo. A invocação que introduzimos diz respeito, como dissemos, à intensificação de uma postura investigativa, que começa com a anamnese das relações individuais com a cultura de história, a cultura escolar de um modo geral, as memórias do ensino de história etc. Para produzir essas anamneses, nos apropriamos de uma metodologia criada por professores da escola básica organizados em um grupo de pesquisa na universidade.

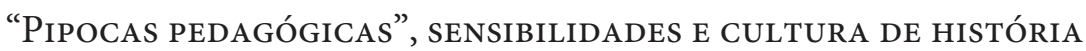

A narrativa a seguir foi produzida, como as outras, com base em um tema preciso. Cada estudante deveria recordar e registrar sua lembrança do contato com meios da cultura de história. Algumas trouxeram ao presente as visitas escolares aos museus, espaços privilegiados da história pública. Vejamos o que lembrou esta estudante: 
Chegamos ao museu, minha primeira visão foi de um museu dentro de um parque, já achei aquilo o máximo; cheio de árvores, próximo de estação de trem, no centro de São Paulo, e fiquei pensando como nunca tinha ido naquele museu que era tão perto do meu ambiente rotineiro... Ao entrar no museu, tivemos o primeiro contato com o guia, um moço muito simpático e que sabia muito sobre o museu. Minha primeira paixão foi pela construção do prédio, aquilo para mim era algo muito impressionante todo em paredes de tijolo a mostra, mas ao mesmo tempo as paredes claras e modernas, com um lustre enorme preto, [e] o guia foi contando para nós quando haviam sido construídas, de que forma as peças dos acervos em exposição foram chegando naquele museu, de quem era cada obra [...]; ele nos foi dando uma aula de história da Pinacoteca. Neste momento olhei para a minha professora Regina que estava com o olhar atento ao que ele dizia para se acaso ele se confundisse em alguma informação histórica ela o corrigiria. [Discente do curso de licenciatura em história, 29 anos, 2017]

Para além do encantamento (reconstruído a partir de uma visão retrospectiva que valoriza esses encontros com o museu ou produto duradouro de seus efeitos sobre os visitantes?), gostaríamos de enfatizar um aspecto. A estudante rememora seu deslumbramento e a competência do educador que dava uma aula sobre a Pinacoteca, mas não deixa de marcar um elemento importante da visitação escolar aos museus: a presença da professora como fiadora das informações oferecidas pelo educador. Essa nota final da narrativa é boa para pensar a questão da autoridade partilhada que caracteriza a história pública. Marcar essa possibilidade indica a abertura da prática investigativa das “pipocas pedagógicas”. A produção, partilha e análise dessas narrativas despretensiosas é um caminho promissor para trazer à tona vozes de diferentes agentes da educação, bem como de ambientes diversos nos quais se dá a elaboração de sentidos relativos ao tempo e à história.

As "pipocas pedagógicas" são narrativas curtas e em primeira pessoa, que evocam de forma fragmentária momentos ou acontecimentos vividos na escola ou pelos agentes da educação, episódios que os tenham tocado intensamente (Campos; Prado, 2013). Elas nasceram nos encontros de professores-pesquisadores do Grupo de Terça, que integram o Grupo de Estudos e Pesquisa em Educação Continuada da Faculdade de Educação da Unicamp (Gepec). Nesse contexto colaborativo, professoras e professores buscavam formas de registrar suas vivências, driblando a escassez de tempo livre em seu cotidiano e criando 
um meio/motivo para continuar a conversa iniciada no encontro. Como categoria que surge da prática reflexiva, elas são chamadas em tom coloquial, porque a elaboração da experiência apareceria quase que espontaneamente, como ideias que "pipocam" na cabeça do professor na medida em que reflete sobre sua prática. Assim, esses registros liminares também nasceram para serem partilhados. E é na interação dialógica que seus sentidos vão se configurando. Portanto, ao mesmo tempo que expressam a resistência de professores à invisibilidade ou ao silenciamento, elas são ato e meio formativo que lança mão da postura reflexiva intersubjetiva, dialógica. Em poucas palavras: em meio à escassez que caracteriza o tempo do trabalho dos educadores, as "pipocas" surgem como lampejos reflexivos e exercício de autoria. Colocadas em diálogo com outras vozes, principalmente do referencial teórico-metodológico discutido em cada circunstância, as narrativas em primeira pessoa potencializam a percepção das complexidades da escola, da educação e do trabalho docente. Como temos trabalhado esse procedimento de investigação nos estágios supervisionados curriculares do curso de História?

Durante os estágios, pedimos aos estudantes que produzam registros sobre o cotidiano escolar, as aulas de história, todo o conjunto, enfim, de elementos usualmente requeridos durante a observação participante. ${ }^{5}$ A essas "pipocas" somam-se as que tematizam especificamente as memórias dos estagiários - lembranças da escola, das aulas de história, do aprendizado histórico em outros espaços, do interesse pela história etc. ${ }^{6} \mathrm{Na}$ verdade, essas memórias precedem as narrativas de observação da escola ou outros ambientes como os museus e as práticas do patrimônio. Como já afirmamos, o questionamento das percepções que carregamos acerca da história, muitas vezes inauditas, inconscientes, começam com a anamnese. A partilha das memórias tem funcionado como prática de rememoração coletiva, na qual os estagiários trazem à tona sensibilidades amalgamadas e educadas historicamente. Durante a discussão, amparada pelas referências e mediada por nossas perguntas, cria-se um ambiente propício a perceber os fios díspares que tecem suas experiências e concepções de mundo para questioná-las. Nesse movimento, vão se imprimindo múltiplos sentidos às experiências formativas e identificando o processo de educação das sensibilidades do qual participamos.

A educação das sensibilidades ou educação política dos sentidos pode ser definida, resumidamente, como um processo educativo que atravessa as 
dimensões sensíveis e racionais dos sujeitos em situações sempre dialógicas. Tendo em vista uma concepção de cultura que é ao mesmo tempo instituída por e instituidora de aspectos sociais, políticos e econômicos da sociedade (Benjamin, 2006), a constituição das sensibilidades é ancorada no tempo e no espaço, o que equivale a dizer que é historicamente engendrada. Ao compreender as sensibilidades como processos que envolvem afetos construídos intersubjetivamente no engajamento com o mundo, questiona-se a percepção comum de que os sentidos e os sentimentos sejam da ordem individual. Ao contrário, sentidos e emoções não são naturais nem estritamente impositivos, pois são variados num mesmo tempo e ao longo da história - as percepções variadas que as expressões artísticas despertam são evidências dessa variação. Em poucas palavras, as sensibilidades são reformulações contínuas, tecidas no encontro dos sujeitos com o mundo, numa afetação mútua que vai moldando as experiências individuais (Gay, 1988; Galzerani, 2016; Cunha, 2016). Qual atenção damos, no ensino de história e na formação dos professores, a esses aspectos da vida humana no tempo? No começo deste artigo já apresentávamos esse questionamento, e deveríamos reconhecer que a insistência da formação nos aspectos conceituais associados ao pensar, à razão, oblitera a mobilização das emoções como parte da experiência histórica. É, portanto, na perspectiva de uma educação das sensibilidades que propusemos os exercícios de rememoração como ponto inicial de muitas das aulas de estágio. Antes de qualquer leitura, as recordações partilhadas trazem a matéria sensível das memórias individuais. Nas (di)visões dessa matéria, especialmente aquelas que se referem aos objetos variados da cultura de história ou da memória cultural, o passado se apresenta como algo que é simultaneamente sentido e pensado.

Uma das 34 narrativas produzidas em um semestre de trabalho, ${ }^{7} \mathrm{em} \mathrm{2017,}$ pode iluminar isso que mencionamos. Ela foi produzida por uma estudante e se intitula "Infância e descoberta do passado":

Lembro que tenho interesse por História desde muito nova. Quando tinha mais ou menos 7 ou 10 anos, gostava de viajar para a cidade da família da minha mãe no interior de Minas Gerais. Nessas ocasiões, meu local preferido para visitar era o cemitério da cidade onde trabalhava um senhor coveiro, do qual não recordo o nome, e hoje já faleceu. Passava tardes inteiras conversando com ele sobre os túmulos, principalmente os túmulos mais antigos do cemitério e ele sempre paciente me explicava. Perguntava: Quem eram as pessoas enterradas ali? O que 
tinham feito no passado? Como era o mundo quando estavam vivas? Foram eles que fundaram a cidade? Como? Pedia explicações sobre os túmulos dessas pessoas e assim eu podia ter um vislumbre da época em que estavam vivas e de quem foram. Quando chegava à casa da minha avó, perguntava ainda mais sobre, pedia para ver objetos antigos da família e gostava de ouvir enquanto me explicavam. [Discente do curso de licenciatura em história, 26 anos, 2017]

Essa narrativa carrega uma marca comum a muitas outras produzidas então: as memórias familiares e a troca intergeracional como estímulo inicial para o interesse sobre história. Ela traz ainda outra marcação comum e que aparece numa das primeiras "pipocas" usadas neste artigo: a cidade como espaço produtivo das relações com a história. Há ainda outros aspectos importantes. Primeiro, a persistência de certa sensibilidade religiosa ou romântica com relação aos passados que se materializam no culto aos mortos. Segundo, os objetos como vetores da memória familiar, como artefatos que, a partir de seu deslocamento com uma simples pergunta, podem servir como mediação entre os tempos. Essa narrativa permite pensar essas dimensões sensíveis da experiência histórica e da reconstrução narrativa que procura dar sentido a ela. Em certo sentido, ao convocar e elaborar essas dimensões sensíveis, estamos na contramão do que normalmente seria o ensino da história na escola ou na universidade, essencialmente centrado no pensamento conceitual, mas nos aproximamos do processo educativo que historiadores e outros profissionais procuram programar nos museus, por exemplo.

O contato intenso com a história apresentada nos games, que também aparece na segunda "pipoca" citada anteriormente, é outra dimensão importante que as narrativas nos revelavam:

Ao versar minhas memórias sobre a história além dos espaços de aprendizagem formais, como por exemplo, a escola, recordo-me de certas lembranças da minha vida. Narro aqui episódios significativos: o ano era de 2005, tinha acabado de ganhar um tal videogame chamado "Playstation 2", que era febre da época, e lá começara minha relação extraclasse com a história, pois apreendia, mesmo sem os games (jogos) terem sido traduzidos para o português, a história. Uma história linear que detinha interpretações e intencionalidades de quem narrava. Ao som dos "Call of Duty 3", "Battlefield 2", que descreviam os conflitos da Primeira Guerra Mundial (1914-1918) e da Segunda Guerra (1939-1945), ou a Guerra Fria 
da franquia “007”. A minha experiência de imersão era fantástica, mas do mesmo modo revelava suas intenções, como nos dois primeiros jogos que citei acima expressava-se uma imagem de um Estados Unidos da América heroico, que chegava e resolvia tudo, ou seja, um único lado de uma história, o "perigo de uma única história" como diria Chimamanda Ngozi. [Discente do curso de licenciatura em história, 21 anos, 2017]

A relação com os games é uma marca geracional importante, que evidencia formas de "imersão" na história próprias à contemporaneidade. Mas há ainda outro aspecto a notar: os jogos eletrônicos também indicam um corte de gênero. Pudemos constatar que, em sua maioria, as referências a esse tipo de material da cultura de história são mais comuns entre os estudantes homens. Nessa narrativa, também percebemos os efeitos da formação, suas referências e aparato conceitual. $\mathrm{O}$ estudante refere-se à ideia de história única, popularizada por um vídeo de Chimamanda Ngozi Adichie (2011), lê os jogos como interpretações com intenções específicas, percebe as narrativas como lineares etc.

Finalmente, trazemos mais uma narrativa em primeira pessoa, que complementa a imagem complexa da cultura de história enunciada já na primeira análise de uma "pipoca", na abertura deste texto. Esta estudante de 32 anos, moradora de Ouro Preto, nos fala de sua relação com a história através dos livros e da própria cidade:

Quando criança, ganhei um livro que contava a história da minha cidade, Ouro Preto. Não consigo me recordar quem me deu o livro, mas foi um presente que eu gostei muito, o livro em questão era Ouro Preto também para crianças, de Maria Zélia Damásio Trindade. Com este livro eu fiz grandes descobertas, aprendi a história de lugares e pessoas que fizeram parte da história da minha cidade e que até então eu não conhecia. Uma das histórias que eu mais gostava no livro era a da revolta de 1720 de Felipe dos Santos e Pascoal da Silva, pois as ruínas das propriedades de Pascoal da Silva, que ficaram conhecidas como Morro da Queimada depois de terem sido incendiadas pelo Conde de Assumar, ficam próximas ao meu bairro. Eu tenho este livro até hoje e penso nele como uma chave que abriu portas para que eu pudesse ir à procura de novas histórias a desvendar e caminhos a percorrer. [Discente do curso de licenciatura em história, 32, 2017] 
A comunicação dessas experiências anteriores e concomitantes ao ensino escolar da história ou com as formas da história pública nos serviu, durante as aulas e agora, para visualizar o emaranhado que compõe as condições de possibilidade para sentir e pensar a história. De cada narrativa individual foi possível recuperar um fio singular: a história presentificada na cidade, nas estátuas, nos cemitérios ou nas ruínas de uma antiga povoação; o passado reconstruído na televisão ou nos videogames; as visitas escolares ou familiares aos museus; a trama da história na vida das famílias, na memória dos mais velhos e nos objetos que lhes servem de amparo. Ao serem apresentadas nas aulas, e também aqui, é possível perceber a historicidade dos atos de recordação como situações em que dois tempos se conjugam e se iluminam. Esse movimento é constitutivo da vida em comum e precisa ser pensado como objeto da história, onde quer que ela seja sistematizada - na escola ou nos ambientes da história pública. Do ponto de vista da formação dos profissionais dedicados a programar a percepção sensível e racional da história, acreditamos ser necessário começar com a voz deles mesmos.

Nesse sentido, portanto, os exercícios de registro das recordações nas "pipocas pedagógicas" constituem momentos de autoria. Além disso, começar cada seção deste texto com as recordações dos estudantes é um gesto que reconhece a potência da metodologia investigativa que tomamos de empréstimo dos professores da escola básica. Ele indica a possibilidade concreta de que a formação de professores pode se alimentar de modelos reflexivos desenvolvidos na escola. Nesse caso, considerando as limitações impostas pelo tempo de trabalho de profissionais da escola básica, as narrativas curtas a registrar reflexões instantâneas sinalizam uma resistência consciente, são um contraponto ao que poderíamos chamar da mais-valia simbólica que, na maioria das situações, caracteriza a docência: a denegação da autoria. Em nossa prática, que aqui tivemos a oportunidade de elaborar conceitualmente, elas serviram de entrada para discussões teoricamente orientadas.

Por fim, podemos dizer que as narrativas produzidas são como anedotas no sentido atribuído por Guimarães Rosa às histórias curtas e engraçadas. $\mathrm{O}$ mestre do romance e do conto, de contos bem curtos como os de Tutameia, via verdade grande nas piadas. E usava uma metáfora aparentemente contraditória para defini-las. As anedotas seriam como um fósforo que, uma vez riscado, perde a serventia. Ele queria ressaltar a verdade instantânea da graça 
que uma piada ou história curiosa desperta e que pode ser gozada individualmente, mas em geral exige um interlocutor. $\mathrm{O}$ riso e a graça são revelações, por assim dizer. Por serem instantâneas, não são verdades menores. Podem ser a porta de acesso para conversas que desdobram outras verdades.

\section{REFERÊNCIAS}

ABREU, Marcelo; RANGEL, Marcelo. Memória, cultura histórica e ensino de história. História \& Cultura, v. 4, n. 2, p. 7-24, set. 2015.

ABREU, Marcelo; BIANCHI, Guilherme; PEREIRA, Mateus. Popularizações do passado e historicidades democráticas: escrita colaborativa, performance e práticas do espaço. Tempo e Argumento, Florianópolis, v. 10, n. 24, p. 279-315, abr./jun. 2018.

ABUD, Kátia. A história nossa de cada dia: saber escolar e saber acadêmico em sala de aula. In: ALMEIDA, Juniele R.; ROVAI, Marta G. e O. (org.). Introdução à história pública. São Paulo: Letra e Voz, 2011.

ADICHIE, Chimamanda Ngozi. The dangers of single history. (Videoconferência). 2011. 18min43s. Disponível em: https://www.ted.com/talks/chimamanda_adichie_the_danger_of_a_single_story/transcript?language=pt. Acesso em: 10 mar. 2019.

ARAÚJO, Valdei; RAMOS, André. A emergência de um ponto de vista cosmopolita: a experiência da História de Portugal na Universal History. Almanack, Guarulhos, $\mathrm{n}$. 10, p. 465-491, ago. 2015.

BENJAMIN, Walter. Teoria do Conhecimento / Teoria do Progresso. In: BENJAMIN, Walter. Passagens. Willi Bolle (org. edição brasileira). Trad. Irene Aron e Cleonice Paes Barreto Mourão. Belo Horizonte: Ed. UFMG; São Paulo: Imesp, 2006. p. 499-530.

BERGER, Stefan; LORENZ, Chris; MELMAN, Billie (dir.). Popularizing National Pasts: 1800 to the Present. New York: Routledge, 2011.

BITTENCOURT, Circe (org.). O saber histórico na sala de aula. São Paulo: Contexto, 2001.

CAMPOS, Cristina Maria; PRADO, Guilherme do V. T. (org.). Pipocas pedagógicas: narrativas outras da escola. São Carlos: Pedro e João Ed., 2013.

CERRI, Luís Fernando. A formação de professores de história no Brasil: antecedentes e panorama atual. História, Histórias, Brasília: UnB, v. 1, n. 2, p. 167-186, 2013.

CIAMPI, Helenice. O presente do passado na formação do professor de História. Revista Territórios \& Fronteiras, Cuiabá: UFMT, v. 8, n. 1, p. 113-130, jan./jun. 2015. 
CONTRERAS, José. A autonomia dos professores. São Paulo: Cortez, 2002.

CUNHA, Nara Rúbia de C. Primaveras compartilhadas: (re)significando a docência na relação com cidade, memórias e linguagens. 2016. Tese (Doutorado em Educação) - Faculdade de Educação, Universidade Estadual de Campinas (Unicamp). Campinas, 2016.

DINIZ-PEREIRA, Júlio Emílio. A construção do campo de pesquisa sobre formação de professores. Revista da FAEEBA - Educação e Contemporaneidade, Salvador: Uneb, v. 22, n. 40, p. 145-154, jul./dez. 2013.

FRISCH, Michael. A Shared Authority: Essays on the Craft and Meaning of Oral History and Public History. Albany: State University of New York Press, 1990.

GABRIEL, Carmem Teresa. O conceito de história ensinada: entre a razão pedagógica e a razão histórica. In: CANDAU, Vera Maria (org.). Reinventar a escola. 5. ed. Petrópolis: Vozes, 2000.

GALZERANI, Maria Carolina B. Entrelazando conocimientos, memorias y práctivas educativas: una producción de culturas docentes. In: PARDO, Maria Benedita L.; GALZERANI, Maria Carolina B.; LOPES, Amélia (org.). Una "nueva" cultura para la formación de maestros: ¿Es posible?. Porto: Livpsic/AMSE-AMCE-WAER, 2008. p. 15-38.

GALZERANI, Maria Carolina B. O Almanaque, a locomotiva da cidade moderna: Campinas, décadas de 1870 e 1880. Campinas: Ed. Unicamp: CMU, 2016.

GAY, Peter. A Experiência Burguesa: da Rainha Vitória a Freud - a educação dos sentidos. São Paulo: Companhia das Letras, 1988.

GRELE, Ronald. Whose public? Whose history? What is the goal of a public historian? The Public Historian, v. 3, n. 1, p. 40-48, Winter 1981.

GUENÉE, Bernard. Histoire et culture historique dans l'Occident médiéval. Paris: Aubier Montaigne, 1980.

HERMETO, Miriam; PEREIRA, Mateus Henrique de F. O ensino de história entre trajetórias e epistemologias: o desafio cotidiano de articular teoria e prática na formação do professor de história. Saeculum Revista de História, João Pessoa: UFPB, n. 27, p. 337-351, jul./dez. 2012.

HUYSSEN, Andreas. En busca del futuro perdido: cultura y memoria en tiempos de globalización. México, DF: Fondo de Cultura Económica, 2007.

LE GOFF, Jacques. História e memória. Campinas, Ed. Unicamp, 2003.

LUCINI, Marizete; OLIVEIRA, Sandra; MIRANDA, Sonia. Na esteira da razão histórica: diálogos e olhares sobre a obra de Jörn Rüsen. In: ZAMBONI, Ernesta (org.). Digressões sobre o ensino de história. Itajaí: Maria do Cais, 2007. 
MATTOS, Ilmar Rohloff. “Mas não somente assim!": leitores, autores, aulas como texto e o ensino-aprendizagem de História. Tempo, Niterói: UFF, v. 11, n. 21, p. 5-16, 2002.

MELMAN, Billie. The Culture of History: English Uses of the Past - 1800-1953. New York: Oxford University Press, 2006.

MONTEIRO, Ana Maria. A história ensinada: algumas configurações do saber escolar. História \& Ensino, Londrina: UEL, v. 9, p. 1-35, 2003.

NADAI, Elza. O Ensino de História no Brasil: trajetória e perspectiva. Revista Brasileira de História, São Paulo: Anpuh, v. 13, n. 26, p. 143-162, 1993.

PALETSCHEK, Sylvia; KORTE, Barbara (dir.). Popular History Now and Then: International Perspectives. S. 1.: Transcript-Verlag, 2012.

PESCE, Marly K. de; ANDRÉ, Marli Elisa D. A. de. Formação do professor pesquisador na perspectiva do professor formador. Formação Docente, Belo Horizonte, v. 4, n. 7, p. 39-50, jul./dez. 2012.

PIMENTA, Selma G.; LIMA, Maria Socorro L. Estágio e docência: diferentes concepções. Revista Poíesis, v. 3, n. 3 e 4, p. 5-24, out. 2006.

RÜSEN, Jörn. História viva: Teoria da História III: formas e funções do conhecimento histórico. Trad. Estevão Martins. Brasília: Ed. UnB, 2010.

SCHMIDT, Maria Auxiliadora. Jörn Rüsen e sua contribuição para a didática da história. Intelligere, v. 3, n. 2, p. 60-76, 2017.

SCHMIDT, Maria Auxiliadora; GARCIA, Tania B. Pesquisas em Educação Histórica: algumas experiências. Educar em Revista, Curitiba: UFPR, v. 1, p. 11-31, 2006.

SETH, Sanjay. Razão ou raciocínio? Clio ou Shiva? História da Historiografia, Ouro Preto, n. 11, p. 173-189, abr. 2013.

VILLALTA, Luiz Carlos. Dilemas da relação teoria e prática na formação do professor de História: alternativas em perspectiva. Revista Brasileira de História, São Paulo: Anpuh, v. 13, n. 25/26, p. 223-232, set. 1992/ago. 1993.

ZEICHNER, Kenneth. Uma análise crítica sobre a "reflexão" como conceito estruturante na formação docente. Educação e Sociedade, Campinas: Unicamp, v. 29, n. 103, p. 535-554, maio/ago. 2008.

ZEICHNER, Kenneth. Políticas de formação de professores nos EUA: como e por que elas afetam vários países do mundo. Belo Horizonte: Autêntica, 2013.

\section{NOTAS}

${ }^{1}$ Doutor em História Social pela Universidade Federal do Rio de Janeiro (UFRJ). 
${ }^{2}$ Doutora em Educação pela Universidade Estadual de Campinas (Unicamp).

${ }^{3}$ Trata-se uma narrativa curta chamada de "pipoca pedagógica" pelo professor Marcemino Bernardo Pereira. Contamos a história dessa denominação mais adiante. Por ora, poderíamos dizer que é uma categoria própria à epistemologia da prática que caracteriza a profissão docente.

${ }^{4}$ Trata-se da Resolução CNE/CP no 1 , de 18 fev. 2002, e da Resolução CNE/CP nº 2, de $1^{\circ}$ jul. 2015.

${ }^{5}$ PIPOCA 2 - Observação Participante. Disponível em: https://docs.google.com/forms/d/1 x6W5CcY6L1vdk4zVflQHF1MNHyxXcRY8NxY1ZR3Gnao/edit?usp=sharing. Acesso em: 10 mar. 2019.

${ }^{6}$ PIPOCA 1 - Memórias da Cultura Histórica (2017). Disponível em: https://docs.google. com/forms/d/1S3-arIrMbzaPMX-2JWiHRr7J195QGk27p3jxQpCIL94/edit?usp=sharing. Acesso em: 10 mar. 2019.

${ }^{7}$ Das 34 respostas de todos os estudantes da turma de estágio supervisionado, 24 autorizaram o uso nas aulas e para fins de pesquisa. Para consultar o conjunto das respostas, ver: Planilha Respostas PIPOCA 1 - Memórias da Cultura Histórica. Disponível em: https:// drive.google.com/file/d/1WGPCVvWMsclgr2sb9LwTR4JDQLFstH7J/view? usp=sharing. Acesso em: 10 mar. 2019.

Artigo recebido em 6 de maio de 2019. Aprovado em 11 de julho de 2019. 